\title{
Analysis Of Key Indicators Of The Insurance Market Of Western Europe
}

https://doi.org/10.21272/sec.5(3).116-125.2021.

Natalia Sidelnyk, ORCID: https://orcid.org/0000-0002-9628-3011

Director of the Sumy Representative Office of the Insurance Company "VUSO”, Ukraine

\begin{abstract}
This paper summarizes the arguments and counterarguments within the scientific discussion on the key indicators of the insurance market. The research's primary purpose is to conduct a comprehensive analysis of the main indicators of the insurance market of Western Europe with the visualization of the results. Insurance markets are adapting to a single trade regime in insurance services. It is formed under the influence of national and regional economic development strategies. The experience of integration in the insurance markets of the European Union shows that not all countries benefit equally from integration processes. The relevance of the decision of this scientific problem is caused by comparative analysis of the share of European countries in the world market by volume insurance premiums. It showed a broad scope, reflecting the high-level asymmetries in the development of the insurance market, as the most developed to less developed countries of Europe. Investigation of the topic of theoretical principles of insurance in the paper is carried out in the following logical sequence: selection of input indicators; analysis of the dynamics and structure of indicators of the insurance market of Western Europe; research of insurance market indicators using correlation and regression analysis; visualization of the results. The research methods' methodological tools were basic descriptive statistics, correlation, and regression analysis. The period of research is 2009-2019. Given the results obtained, we can say that the dynamics of change in the studied indicators are abrupt. Some indicators have a clear trend to change, in particular, the share of life insurance. Given the structural analysis, the following results were obtained. The largest share of the country's insurance market share among OECD countries is observed in the following countries: Germany and France. The Czech Republic and Latvia occupy the smallest share in this indicator. Correlation-regression analysis shows an increase in the total number of insurance premiums (fees for the insurance company's services) shows an increase in the general interest of the population in insurance services, which will contribute to the growth of all areas of insurance.
\end{abstract}

Keywords: insurance, insurance market, finance, financial market, financial flow.

JEL Classification: E44, G22.

Cite as: Sidelnyk, N. (2021). Analysis Of Key Indicators Of The Insurance Market Of Western Europe. SocioEconomic Challenges, 5(3), 116-125. https://doi.org/10.21272/sec.5(3).116-125.2021.

$\begin{array}{lll}\text { Received: 27.07.2021 Accepted: 12.09.2021 } & \text { Published: 13.09.2021 }\end{array}$

(c) (i)

Copyright: (C) 2021 by the author. Licensee Sumy State University, Ukraine. This article is an open access article distributed under the terms and conditions of the Creative Commons Attribution (CC BY) license (https://creativecommons.org/licenses/by/4.0/).

\section{Introduction}

With the intensification of globalization, there is a need for cooperation between countries to increase the resilience of national financial systems. Participation in integration associations has a positive effect on the economy of each member state in connection with the growth of mutual trade, lower prices for several goods and services, increasing consumer choice, the emergence of incentives to innovate (as a result of increased competition) and expanding markets sales. Among the negative consequences is the effect of trade diversions associated with the expulsion of domestic producers from the market, the imposition of "rules of the game" on more developed countries less developed. Insurance markets are adapting to a single trade regime in insurance 
services, which is formed under the influence of national and regional economic development strategies. The experience of integration in the insurance markets of the European Union shows that not all countries benefit equally from integration processes. The best strategic and tactical issues of European insurers are inextricably linked and reinforce each other. The principal value proposals of insurers, market-entry, and approach to resource allocation, labor strategy, and data of the technological environment should be considered as a single symbiotic entity. Individual forces cannot control macroeconomic conditions, geopolitical development, technological progress, demographic change, and growing customer expectations. The same applies to factors of competition and convergence of the industry: insurance is increasingly affected by trends and changes in other sectors and vice versa. In the context of the global pandemic, the following issues are relevant for the development of the economy in general and the insurance sector in particular: the rapid pace of economic recovery creates a need for private and commercial customers in new insurance products. In addition, regulatory oversight is being strengthened, and new reporting requirements are being formulated, forcing insurers to reconsider how they manage performance. The work aims to conduct a comprehensive analysis of the leading indicators of the insurance market of Western Europe with the visualization of the results. To achieve this goal it is necessary to solve the following tasks: to form tasks and the insurance market array indicators of Western Europe; to analyze the dynamics and structure of indicators; to study the indicators using correlation and regression analysis; to visualize the results of the analysis.

\section{Literature Review}

With the development of transformation processes in the financial market, some traditional financial transactions began to be performed not only by financial institutions but also by non-financial entities. To provide a comprehensive range of financial services and increase competitiveness in the financial services market, many financial institutions modify their activities so that the consumer can get a full range of services (Abeysekera, 2020; Agnihotri \& Gupta, 2019; Dudchenko, 2020; Ciubotariu et al., 2019). Two factors determine the insurance market as an integral part of the financial system. First, there is an objective need for insurance protection, which leads to the creation of an insurance market in the socio-economic system of society (Bagmet \& Haponova, 2018; Molotok, 2020; Popoola et al., 2019; Zolkover \& Renkas, 2020). Second, the monetary form of insurance protection directly connects this market with the general financial market (Yanyshyn et al., 2019; Goncharenko, 2020; Vargas-Hernández \& Rodríguez, 2018). The modern insurance market is closely connected with innovative technologies, mainly information and communication through the Internet. Internet insurance is a segment of the electronic financial market that uses Internet technologies to provide virtual communication between the client and the insurance company to select the required insurance product and further service (Delanoy \& Kasztelnik, 2020; Giebe et al., 2019; Mihalcova et al., 2020; Njegovanović, 2018; Porrini, 2020; Rehman, 2020; Starostina et al., 2020). Innovative solutions implemented in the field of insurance do not always correlate with the readiness of the population (Didenko \& Sidelnyk, 2021; Korcsmaros et al., 2019; Singh, 2021) and the market as a whole (Kljucnikov \& Majkova, 2018; Moskovicz, 2019; Umadia \& Kasztelnik, 2020). Despite a reasonably wide range of research and a significant amount of work related to the analysis of processes occurring in the insurance market, this area is constantly in need of deepening.

\section{Methodology and research methods}

Given the goal of researching the insurance market in Western Europe, the following procedure should be followed. First, define an array of input data. Second, with the help of descriptive statistics and absolute growth, growth rate and growth to analyze the dynamics of change and the structure of indicators. Third, with the help of correlation-regression analysis to formalize the functional relationships between variables.

The input data are indicators that characterize ten Western European countries (Austria, Belgium, Czech Republic, Denmark, France, Germany, Ireland, Latvia, Norway) during 2009 - 2019. The source of the information base for the study is the Organization for Economic Cooperation and development (Table 1). 
Table 1. Input array

\begin{tabular}{|c|c|c|c|c|c|c|}
\hline Years & $\begin{array}{c}\text { Market share } \\
\text { in OECD, \% } \\
\text { (I1) }\end{array}$ & $\begin{array}{c}\text { Market share of } \\
\text { foreign } \\
\text { branches/agencies } \\
\text { of foreign } \\
\text { undertakings in } \\
\text { total domestic } \\
\text { business, \% (I2) }\end{array}$ & $\begin{array}{c}\text { Direct total gross } \\
\text { premiums/Number } \\
\text { of employees of } \\
\text { insurance } \\
\text { companies, дол. } \\
\text { (I3) }\end{array}$ & $\begin{array}{c}\text { Life } \\
\text { insurance } \\
\text { share, \% } \\
\text { (I4) }\end{array}$ & $\begin{array}{c}\text { Penetration, } \\
\% \text { (I5) }\end{array}$ & $\begin{array}{c}\text { Density, } \\
\text { dol. (I6) }\end{array}$ \\
\hline 2009 & 2,25 & 43,00 & 87587,09 & 42,93 & 7,67 & 3727,63 \\
\hline 2010 & 2,25 & 42,42 & 1106812,25 & 46,40 & 7,63 & 3696,77 \\
\hline 2011 & 2,00 & 37,07 & 2251524,73 & 54,02 & 7,55 & 4153,98 \\
\hline 2012 & 2,03 & 38,12 & 2212886,20 & 52,40 & 7,57 & 3938,55 \\
\hline 2013 & 2,58 & 36,08 & 2256833,17 & 56,03 & 7,48 & 4013,39 \\
\hline 2014 & 2,16 & 38,09 & 1348415,06 & 54,02 & 7,89 & 4339,04 \\
\hline 2015 & 1,89 & 38,40 & 1200167,06 & 52,97 & 7,37 & 3709,61 \\
\hline 2016 & 1,91 & 42,19 & 1693056,71 & 50,37 & 7,58 & 3875,26 \\
\hline 2017 & 1,90 & 37,65 & 2091172,49 & 50,52 & 7,18 & 3870,90 \\
\hline 2018 & 2,04 & 37,85 & 2536110,13 & 49,20 & 6,86 & 3954,97 \\
\hline 2019 & 2,13 & 37,90 & 2159299,34 & 48,71 & 6,89 & 3854,41 \\
\hline
\end{tabular}

Sources: OECD.

To analyze the dynamics, absolute growth, growth rate, and growth rate - basic and chain, respectively, were calculated.

\section{Results}

The share of foreign insurance companies during the study period has a negative trend. Only in 2016, there is a slight jump of $10 \%$, but after 2016 and until 2019, this figure began to decline again. The second indicator, the share of life insurance, increased for all countries until 2013, and after that year began to decrease by about $0.5 \%$ annually gradually. The ratio of total insurance premiums to GDP decreased by only $0.1 \%$ over eleven years, with slight fluctuations. Thus, all changes with the indicators of the insurance market of Western Europe are not explicit and generally do not violate the general market trend. The values of absolute growth and growth rate allow us to analyze the dynamics of change in indicators. Let's present them graphically to ensure that the conclusions obtained in the first section are correct (figures 1 - 2).

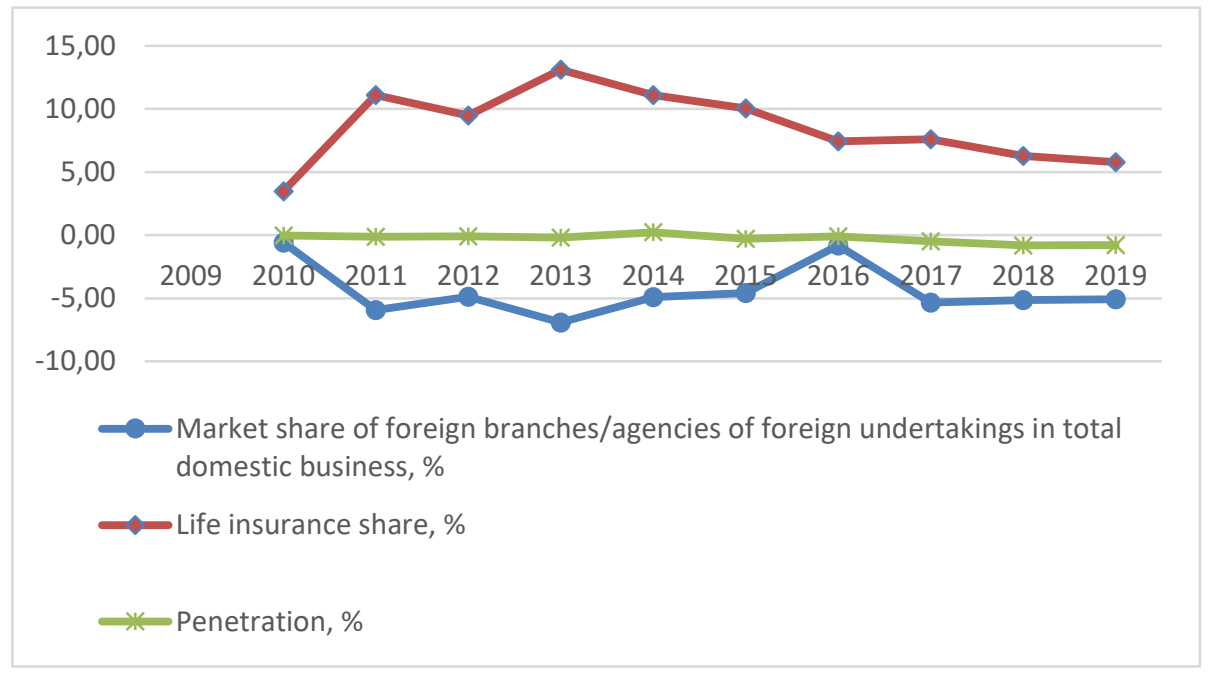

Figure 1. Visualization of the absolute growth of the insurance market in Western Europe

Sources: own calculations. 


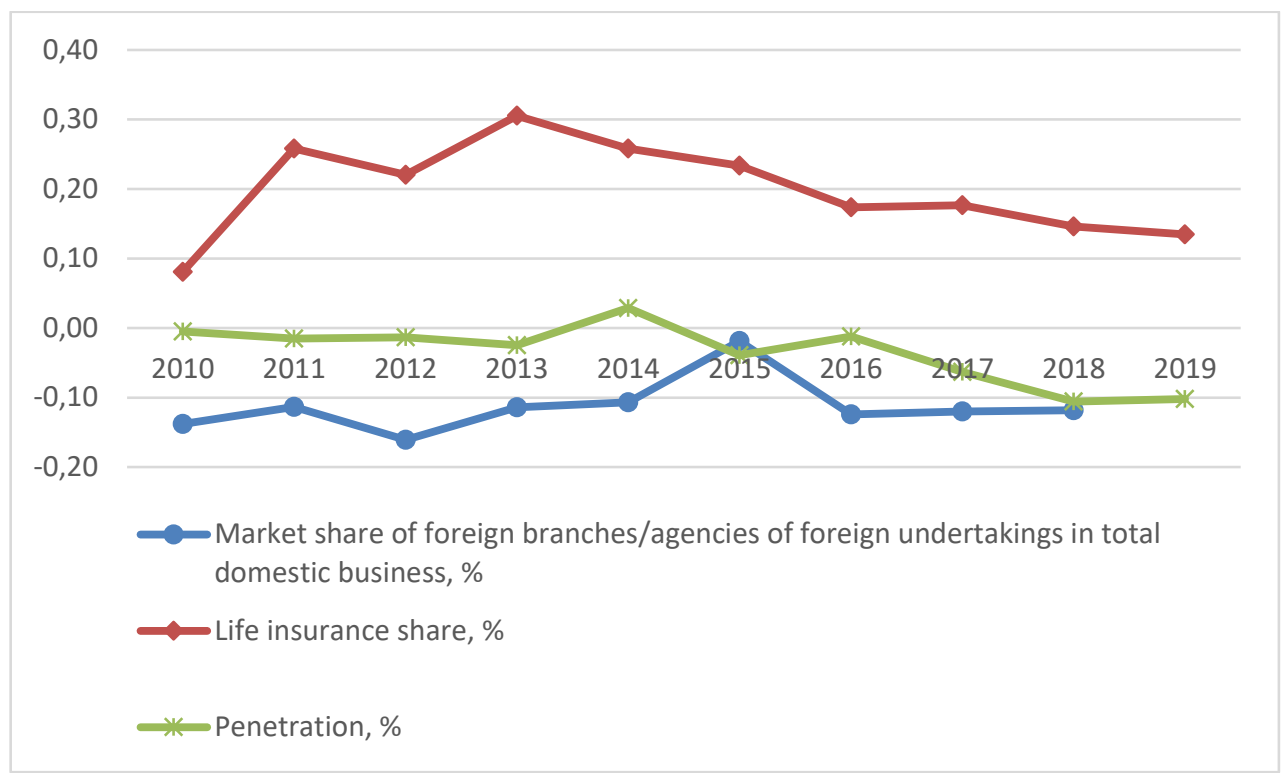

Figure 2. Visualization of the growth rate of the insurance market in Western Europe

Sources: own calculations.

To conduct a structural analysis, we examine the share of the country's insurance market among OECD countries and the volume of insurance premiums to the total population in Western Europe. The table with the input data and the obtained results is presented below (Table 2).

Table 2. The results of structural analysis

\begin{tabular}{|l|c|c|c|c|}
\hline \multicolumn{1}{|c|}{ Country } & $\begin{array}{c}\text { Market share in } \\
\text { OECD, \% }\end{array}$ & $\begin{array}{c}\text { Specific weight of } \\
\text { market share in } \\
\text { OECD, \% }\end{array}$ & Density, dol. & $\begin{array}{c}\text { Specific weight of } \\
\text { density, \% }\end{array}$ \\
\hline Austria & 1,22 & 6,87 & 2010,17 & 5,97 \\
\hline Belgium & 0,70 & 3,94 & 2852,61 & 8,47 \\
\hline Czech Republic & 0,14 & 0,81 & 663,44 & 1,97 \\
\hline Denmark & 0,77 & 4,33 & 6485,82 & 19,25 \\
\hline France & 6,62 & 37,28 & 4471,83 & 13,27 \\
\hline Germany & 6,86 & 38,60 & 3095,08 & 9,19 \\
\hline Ireland & 0,99 & 5,60 & 9492,24 & 28,18 \\
\hline Latvia & 0,02 & 0,11 & 497,20 & 1,48 \\
\hline Norway & 0,44 & 2,47 & 4119,54 & 12,23 \\
\hline Austria & 17,77 & 100,00 & 33687,92 & 100,00 \\
\hline
\end{tabular}

Sources: own calculations.

The structural analysis helped to receive the following results. As we can see, the largest share of the country's insurance market share among OECD countries is observed in the following countries: Germany - 38.60\% and France $-37.28 \%$. The smallest share in this indicator is occupied by the Czech Republic and Latvia - $0.81 \%$ and $0.11 \%$, respectively. This situation can be explained by the insufficient level of development of the insurance market in these countries. Regarding insurance premiums to the total population, the leading positions are occupied by Ireland (28.18\%) and Denmark (19.25\%). The Czech Republic (5.97\%) and Latvia (1.48\%) lag far behind these countries, confirming the insurance sector's imperfection in these countries.

The following graph shows the structure of the country's insurance market share among the OECD countries of the studied countries of Western Europe in 2019 (Figure 3). 


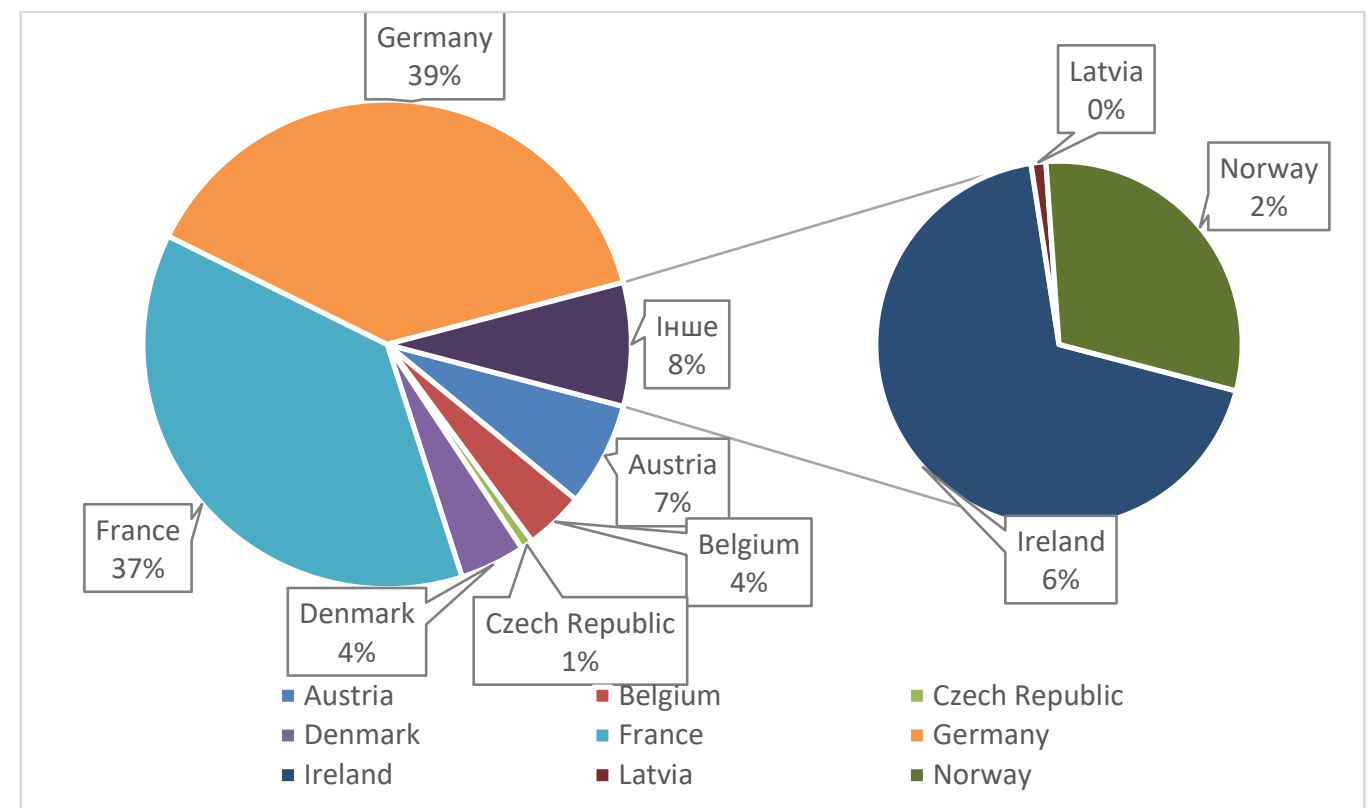

Figure 3. Visualization of the structure of the country's insurance market share among the OECD countries of the studied countries of Western Europe in 2019

Sources: own calculations.

In the next step of the study, we will analyze the descriptive statistics for the studied indicators. Some indicators of the country's insurance market share among OECD countries:

non-variable (the difference between the maximum and minimum values is less than one);

$>$ does not correspond to the normal distribution law (values of excess and asymmetry are greater than zero);

$>$ standard deviation and variance confirm the thesis on the variation of the series and inconsistency with the normal distribution law.

A number of shares of foreign insurance companies:

$>$ variable (the difference between the maximum and minimum values is more than 7 units);

$>$ does not correspond to the normal distribution law (values of excess and asymmetry are negative);

$>$ standard deviation and variance confirm the thesis of significant series variation and inconsistency with the normal distribution law.

A number of total insurance premiums to the number of employees in the insurance sector:

$>$ has a significantly variable (maximum value exceeds its minimum twice);

$>$ does not correspond to the normal distribution law (values of excess and asymmetry are different from zero);

$>$ standard deviation and variance confirm the thesis on the minimum variation of the series and inconsistency with the normal distribution law.

Life insurance share:

$>$ has a variable range (the difference between the maximum and minimum values is about 14 units);

$>$ does not correspond to the normal distribution law (values of excess and asymmetry are different from zero);

$>$ standard deviation and variance confirm the thesis of significant series variation and inconsistency with the normal distribution law.

A number of ratios of total insurance premiums to GDP:

$>$ has a not significantly variable range (the difference between the maximum and minimum values is about one);

$>$ does not correspond to the normal distribution law (values of excess and asymmetry are different from zero);

$>$ standard deviation and variance confirm the thesis of a slight variation of the series and inconsistency with the normal distribution law. 
A number of insurance premiums to the total population:

$>$ has a significantly variable range (the difference between the maximum and minimum values is more than 600 units);

$>$ does not correspond to the normal distribution law (values of excess and asymmetry are different from zero);

$>$ standard deviation and variance confirm the thesis of significant series variation and inconsistency with the normal distribution law.

The values of the share of foreign insurance companies, the volume of total insurance premiums to the number of employees in the insurance sector, and the percentage of life insurance are the most variable. The least variable is the value of insurance premiums to the total population. Such heterogeneity of indicators that characterize the insurance market indicates a difference in the level of economic development of certain countries. Thus, even though the studied countries of Western Europe belong to the group of countries with a high level of economic development, they differ significantly from each other in the level of growth of the insurance market. Correlationregression analysis was chosen to analyze indicators, which best allows studying the functional dependence between variables. First, we construct a correlation matrix, the elements of which are pairwise correlation coefficients, representing a measure of the relationship between direction and density. The correlation matrix for the studied indicators is presented in the following table (Table 3).

Table 3. The results of correlation analysis in the form of a correlation matrix

\begin{tabular}{|c|c|c|c|c|c|c|}
\hline & I1 & I2 & I3. & I4 & I5 & I6 \\
\hline I1 & 1,00 & $-0,37$ & 0,02 & $-0,15$ & $-0,03$ & $-0,06$ \\
\hline I2 & $-0,37$ & 1,00 & $-0,81$ & $-0,76$ & $-0,77$ & $-0,84$ \\
\hline I3 & 0,02 & $-0,81$ & 1,00 & 0,82 & 0,97 & 0,96 \\
\hline I4 & $-0,15$ & $-0,76$ & 0,82 & 1,00 & 0,86 & 0,93 \\
\hline I5 & $-0,03$ & $-0,77$ & 0,97 & 0,86 & 1,00 & 0,97 \\
\hline I6 & $-0,06$ & $-0,84$ & 0,96 & 0,93 & 0,97 & 1,00 \\
\hline
\end{tabular}

As you can see, the correlation coefficient between almost all insurance market indicators shows a close (more than 0.7) statistically significant relationship. To confirm the results of the correlation analysis, we present a matrix scattering diagram (Figure 4).
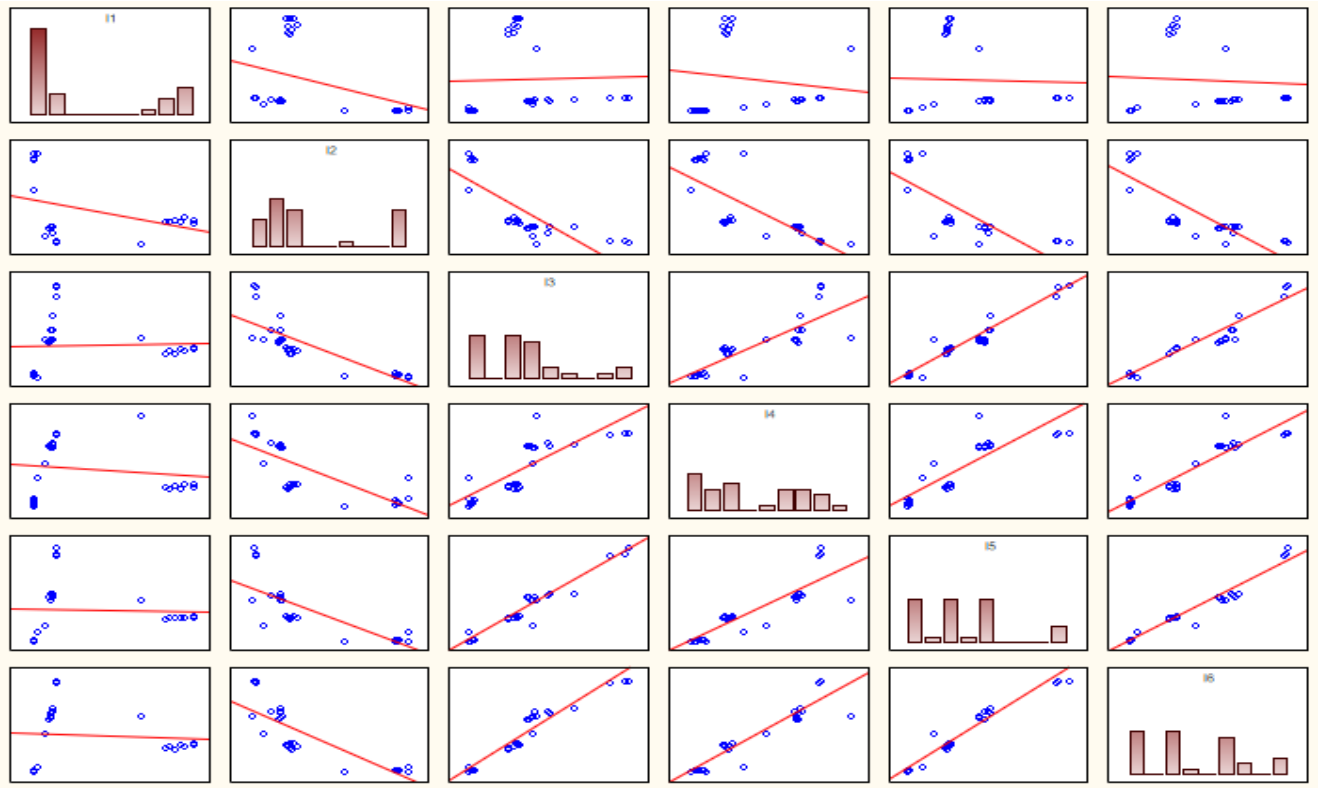

Figure 4. Scattering diagram

Source: own calculations.

In the next step, we formalize the identified relationships between indicators. 
The main purpose of regression analysis is to identify the causal relationship between variables and demonstrate its strength. To formalize the relationship between variables, we use the regression model (1):

$$
Y=\alpha+\beta X+\varepsilon_{i},
$$

where $Y$-dependent variable; $\beta$ - regression equation coefficient; $X_{i}-i$ independent variable; $\varepsilon$ - standard error.

For regression analysis, we use the following indicators. According to the results of correlation analysis as a dependent variable, the indicator Life insurance share, $\%(Y)$, was used. As independent variables, those indicators that have the highest value of the correlation coefficient with a particular dependent variable - Direct total gross premiums / Number of employees of insurance companies (I3); Penetration,\% (I5), and Density (I6). For the study, we construct three one-factor regression equations.

The results of the first model:

$>$ the normalized coefficient of determination is equal to 0.31 , which means the presence of low accuracy of approximation and reliability of the obtained simulation results;

$>$ the calculated value of the Fisher criterion is greater than its tabular value for these degrees of freedom (3.28), which means the presence of statistical significance of the constructed model;

$>$ the level of $p$ is less than 0.05 , i.e., the parameter of the regression equation is statistically significant.

The results of the second model:

$>$ the normalized coefficient of determination is equal to 0.53 , which indicates the average reliability and approximation of the results;

$>$ the calculated value of the Fisher criterion is greater than its tabular value for these degrees of freedom, which means the presence of statistical significance of the constructed model;

$>$ the level of $\mathrm{p}$ is much less than 0.05 , ie, the parameter of the regression equation is statistically significant.

The results of the third model:

$>$ the normalized coefficient of determination is equal to 0.62 , which indicates fairly high accuracy of approximation;

$>$ the calculated value of Fisher's criterion is greater than its tabular value of these degrees of freedom, which means the presence of statistical significance of the constructed model.

$>$ the level of $\mathrm{p}$ is much less than 0.05 , i.e., the parameter of the regression equation is statistically significant.

Given the regression analysis results, the model is best approximated. The independent variable was the volume of insurance premiums to the total population, as the dependent variable changed by more than $62 \%$ due to the difference in the independent variable.

The most substantial relationship is observed between the number of insurance premiums to the total population and the share of life insurance (third model) because the coefficient of determination is the highest for this pair of indicators. The regression equation, in this case, will look like this (2):

$Y=32,3+0,005 X 3$

We present the causal relationship between the number of insurance premiums graphically to the total population per unit and the share of life insurance, using a combined graph (bar chart and line chart with labels) (Figure 5). 


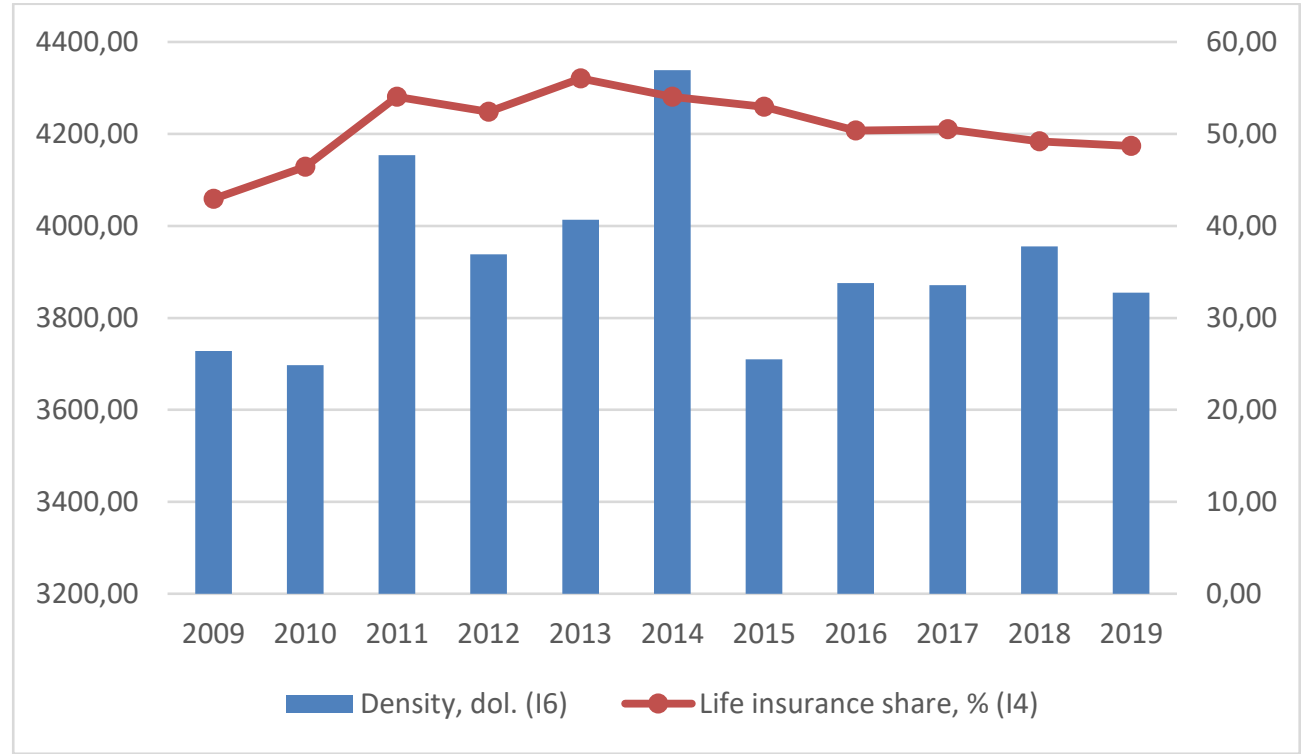

Figure 5. Visualization of the relationship between the amount of insurance premiums to the total population per unit and the share of life insurance in the studied countries of Western Europe (2009-2019)

Sources: own calculations.

Thus, with the increase in the volume of insurance premiums to the total population per unit, the share of life insurance for Western Europe will increase by $0.005 \%$. This result reflects the reality, as the growth of the total number of insurance premiums (fees for the insurance company's services) indicates an increase in the general interest of the population in insurance services, which will contribute to the growth of all areas of insurance.

\section{Conclusion}

The study of insurance market indicators in Western Europe took place in two stages: a detailed statistical analysis of data and visualization of the results. First, an information base for the analysis of the indicators of the insurance market of Western Europe during 2009 - 2019 was formed. The source of the information base for the study is the Organization for Economic Cooperation and Development data. A total of 6 indicators were selected for the study. Secondly, the dynamics and structure of the leading indicators of the insurance market of Western Europe are analyzed. Given the results obtained, we can say that the dynamics of change in the studied indicators are abrupt. Some indicators have a clear trend to change, in particular, the share of life insurance. Given the structural analysis, the following results were obtained. The largest share of the country's insurance market share among OECD countries is observed in the following countries: Germany - 38.60\% and France $-37.28 \%$. The smallest share in this indicator is occupied by the Czech Republic and Latvia - $0.81 \%$ and $0.11 \%$, respectively. This situation can be explained by the insufficient level of development of the insurance market in these countries.

Regarding the ratio of insurance premiums to the total population, the leading positions are occupied by Ireland (28.18\%) and Denmark (19.25\%). The Czech Republic (5.97\%) and Latvia (1.48\%) lag far behind these countries, confirming the insurance sector's imperfection in these countries. Third, the correlation analysis allowed us to conclude that there is a close relationship between all indicators. A statistically significant correlation was found between all studied variables. Still, the best approximation of the results was observed between the number of insurance premiums to the total population and the share of life insurance. The constructed regression model allowed to reveal a significant approximation of the results between the variables. The evolution of the independent one explains the change of the dependent variable by more than $62 \%$. With the increase in insurance premiums to the total population per unit, the share of life insurance for Western Europe will increase by $0.005 \%$. This result reflects the reality, as the growth of the total number of insurance premiums (fees for the insurance company's services) indicates an increase in the general interest of the population in insurance services, which will contribute to the growth of all areas of insurance. 
Funding: self-funded.

Author contribution: conceptualization, Natalia Sidelnyk; data curation, Natalia Sidelnyk; formal analysis, Natalia Sidelnyk; funding acquisition, Natalia Sidelnyk; investigation, Natalia Sidelnyk; methodology, Natalia Sidelnyk; project administration, Natalia Sidelnyk; resources, Natalia Sidelnyk; software, Natalia Sidelnyk; supervision, Natalia Sidelnyk; validation, Natalia Sidelnyk; visualization, Natalia Sidelnyk; writing - original draft, Natalia Sidelnyk; writing - review \& editing, Natalia Sidelnyk.

\section{References}

1. Abeysekera, R. (2020). Co-Production Related To Business Counselling in Microfinance Sector As A Demonstration Of Globalization And Social Cooperation: An Interpersonal Relationship Approach. SocioEconomic Challenges, 4(2), 56-66. [CrossRef], [Google Scholar].

2. Agnihotri, A., Gupta, S. (2019). Relationship of Corporate Governance and Efficiency of Selected Public and Private Sector Banks in India. Business Ethics and Leadership, 3(1), 109-117. [CrossRef], [Google Scholar].

3. Bagmet, K.V., Haponova, O. (2018). Assessing the Impact on Social Sector: A Macroeconomic Approach. SocioEconomic Challenges, 3(2), 103-108. [CrossRef], [Google Scholar].

4. Ciubotariu, M., Socoliuc, M., Mihaila, S., Savchuk, D. (2019). Companies Image: Marketing and Financial Communications. Marketing and Management of Innovations, 3, 223-241. [CrossRef], [Google Scholar].

5. Delanoy, N., Kasztelnik, K. (2020). Business Open Big Data Analytics to Support Innovative Leadership Decision in Canada. Business Ethics and Leadership, 4(2), 56-74. [CrossRef], [Google Scholar].

6. Didenko, I., Sidelnyk, N. (2021). Society's Readiness for Modern Challenges of the Insurance Market: Bibliometric Analysis. Financial Markets, Institutions and Risks, 5(1), 116-125. [CrossRef], [Google Scholar].

7. Dudchenko, V.Yu. (2020). Interaction of Central Bank Independence and Transparency: Bibliometric Analysis. Business Ethics and Leadership, 4(2), 109-115. [CrossRef], [Google Scholar].

8. Giebe, C., Hammerström, L., Zwerenz, D. (2019). Big Data \& Analytics as a sustainable Customer Loyalty Instrument in Banking and Finance. Financial Markets, Institutions and Risks, 3(4), 74-88. [CrossRef], [Google Scholar].

9. Goncharenko, T. (2020). From Business Modelling to the Leadership and Innovation in Business: Bibliometric Analysis (Banking as a Case). Business Ethics and Leadership, 4(1), 113-125. [CrossRef], [Google Scholar].

10. Kljucnikov, A., \& Majkova, M. S. (2018). Funding Risk Perception by Slovak SMEs: Impact of Age and Size of the Company. Marketing and Management of Innovations, 4, 282-297. [CrossRef], [Google Scholar].

11. Korcsmaros, E., Seben, Z., Machova, R., Feher, L. (2019). Promotion of Euro Introduction in Slovakia: Financial Literacy of Generation X and Y. Marketing and Management of Innovations, 3, 11-21. [CrossRef], [Google Scholar].

12. Mihalcova, B., Gallo, P., \& Lukac., J. (2020). Management of Innovations in Finance Education: Cluster Analysis for OECD Countries. Marketing and Management of Innovations, 1, 235-244. [CrossRef], [Google Scholar].

13. Molotok, I. (2020). Analysis Of The Relevance Of Fiscal Decentralization In Ensuring Country Investment Attractiveness. SocioEconomic Challenges, 4(2), 99-105. [CrossRef], [Google Scholar].

14. Moskovicz, A. (2019). Financial Qualitative Research: A Comprehensive Guide for Case Study usage. Financial Markets, Institutions and Risks, 3(4), 106-116. [CrossRef], [Google Scholar].

15. Njegovanović, A. (2018). Digital Financial Decision With A View Of Neuroplasticity / Neurofinancy / Neural Networks. Financial Markets, Institutions and Risks, 2(4), 82-91. [CrossRef], [Google Scholar].

16. Popoola, M. Ak., Brimah, Am. N., Gbadeyan, A. R. (2019). Financial Institutions Micro Loans: A Strategy for Reducing Poverty in Nigeria. Financial Markets, Institutions and Risks, 3(3), 13-17. [CrossRef], [Google Scholar].

17. Porrini, D. (2018). The effects of innovation on market competition: the case of the insurance comparison websites. Marketing and Management of Innovations, 3, 324-332. [CrossRef], [Google Scholar]. 
18. Rehman, A. (2020). Innovation and Management by Regional Rural Banks in Achieving the Dream of Financial Inclusion in India: Challenges and Prospects. Marketing and Management of Innovations, 1, 222234. [CrossRef], [Google Scholar].

19. Singh, S.N. (2021). Women in Micro and Small Business Enterprises and their Financial Cruxes in Ethiopia: A Case Study of Mettu Town. Financial Markets, Institutions and Risks, 5(1), 98-115. [CrossRef], [Google Scholar].

20. Starostina, A., Pikus, R., \& Kravchenko, V. (2020). Innovative Activities within Ukrainian Insurance Companies. Marketing and Management of Innovations, 2, 44-55. [CrossRef], [Google Scholar].

21. Umadia K. Sr., Kasztelnik, K. (2020). The Financial Innovative Business Strategies of Small to Medium Scale Enterprises in Developing Country and Influence for the Global Economy Performance. SocioEconomic Challenges, 4(3), 20-32. [CrossRef], [Google Scholar].

22. Vargas-Hernández, J. G., Rodríguez, C. R. F. (2018). Leadership Styles as a Challenge to Generate Innovation Environments in the Companies of the 21st Century. Business Ethics and Leadership, 2(4), 64-73. [CrossRef], [Google Scholar].

23. Yanyshyn, Y., Bryk, H. \& Kashuba, Y. (2019). Problems and Perspectives of Internet-Insurance in Ukraine. Marketing and Management of Innovations, 4, 31-38. [CrossRef], [Google Scholar].

24. Zolkover, A., Renkas, J. (2020). Assessing The Level Of Macroeconomic Stability Of EU Countries. SocioEconomic Challenges, 4(4), 175-182. [CrossRef], [Google Scholar]. 